\title{
Sid New Disease Reports \\ First report of Apple scar skin viroid (ASSVd) in apple trees in Argentina
}

\author{
C. Nome ${ }^{1 *}$, A. Giagetto ${ }^{2}$, M. Rossini ${ }^{1}$, L. Di Feo $^{1}$ and A. Nieto ${ }^{1}$ \\ ${ }^{1}$ Instituto Nacional de Tecnología Agropecuaria (INTA). Instituo de Patología Vegetal (IPAVE) Camino 60 cuadras, km 5,5. \\ X5020ICA. Córdoba. Argentina; ${ }^{2}$ Instituto Nacional de Tecnología Agropecuaria (INTA). Estacion Experimental \\ Agropecuaria Alto Valle. Ruta Nac. 22 Km 1190 (8332) Allen, Río Negro, Argentina
}

*E-mail: cfnome@yahoo.com.ar

Received: 04 Nov 2011. Published: 27 Jan 2012. Keywords: pome fruit diseases, Malus domestica, Apscaviroid

In the course of screening forviroidspresent inArgentina, apple trees (Malus domestica) from five orchards located in Allen (Alto Valle), Rio Negro province, Argentina, were randomly tested for Apple scar skin viroid (ASSVd) during December 2009 and January 2010. The following apple cultivars were examined (number of trees in brackets): Chañar-34 (a Red Delicious clone) (12), Red Sensation (6), Gala (22) and Red Delicious (6). None of the sampled trees had fruits yet, so no viroid symptoms were observed. When dsRNA-enriched leaf preparations (Pallás et al., 1987) were analysed by dot-blot hybridisation with a digoxigenin-labelled riboprobe specific for ASSVd, 19 samples (six of Chañar-34, eight of Gala, and five of Red Delicious) tested positive for the viroid. As negative control, dsRNA from virus-free apple trees was used and showed no reaction. (These healthy trees belong to a phytosanitary project that is being conducted in INTA).Two of the dsRNA preparations with intense dot-blot signals from cv. Gala samples were analysed by double electrophoresis, first in non-denaturing and then in denaturing 5\% polyacrylamide gels (Pallás et al., 1987). Staining with ethidium bromide revealed a band in the position expected for a viroid RNA.

The segment corresponding to the band of the two samples was excised and electroeluted. Two-step (RT)-PCR amplification using Moloney-murine leukaemia virus (M-MLV) reverse-transcriptase (Promega Corporation, Madison, Wisconsin, USA), DNA polymerase (Promega, GoTaq ${ }^{\circledR}$ Hot Start Polymerase) and primers VirPom- $\mathrm{F}$ (5'-TCGTCGTCGACGAAGG-3') and VirPom-R (5'-GAGCACCACAGGAACCTCACGG-3') generated a product of the size expected (267 bp) for ASSVd(Faggioli et al., 2001). The product was cloned into pUC 19 (Fermentas Life Sciences), following manufacturer's instructions, and sequenced by the Unidad de Genómica, Instituto de Biotecnología (Argentina). The analysis of four clones, two for each sample, was done using the EditSeq and MegAlign programs of DNASTAR ver. 8.0.2 (DNASTAR, Madison, Wis.). The consensus sequence (GenBank Accession No. HQ606078) of 267 bp, had 97\% similarity with a Chinese ASSVd isolate from pear (EU031476). ASSVd is a 330-nucleotide member of the genus Apsacaviroid (family
Pospiviroidae), that induces serious diseases on pome fruit trees such as apple scar skin, dapple apple, pear rusty skin and pear dimple fruit in Europe, Asia and North America. It has been additionally detected in Malus sylvestris and Pyrus amygdaliformis (Desvignes et al., 1999) and, more recently, in cherry and apricot (Kaponi et al., 2010). Economic losses are due to damage to fruit (Koganezawa et al., 2003). This report of ASSVd, which to our knowledge is the first in Argentina and even in South America, indicates the need for careful testing of apple propagation material to avoid spreading of this pathogen.

\section{References}

Desvignes JC, Grasseau N, Boyé R, Cornaggia D, Aparicio F, Di Serio F, Flores R, 1999. Biological properties of apple scar skin viroid: isolates, host range, different sensitivity of apple cultivars, elimination, and natural transmission. Plant Disease 83, 768-772.

[doi:10.1094/PDIS.1999.83.8.768]

Faggioli F, Ragozzino E, Barba M, 2001. Simultaneous detection of stone or pome fruit viroids by single tube-RT-PCR. Acta Horticulturae 550, 59-64

Kaponi MS, Luigi M, Barba M, Sano T, Kyriakopoulou PE, 2010. First report and molecular analysis of apple scar skin viroid in sweet cherry. Julius-Kühn Archives 427, 361-365.

Kaponi MS, Luigi M, Barba M, Sano T, Kyriakopoulou PE, 2010. First report and molecular analysis of apple scar skin viroid in sweet cherry. Julius-Kühn Archives 427, 361-365.

Pallás V, Navarro A, Flores R, 1987. Isolation of a viroid-like RNA from hop different from hop stunt viroid. Journal of General Virology $\mathbf{6 8}$, 3201-3205. [doi:10.1099/0022-1317-68-12-3201] 